\title{
Gradients in Traits Composition and Their Relation to Environmental Complex-Gradients and Structuring Processes: a Study of Marine Sediment Species Communities
}

\author{
Thijs Christiaan van Son ${ }^{1,2, *}$, Eivind Oug ${ }^{3}$, Rune Halvorsen ${ }^{2}$ and Fredrik Melsom ${ }^{1}$ \\ ${ }^{1}$ Marine Biology Program, Department of Biosciences, University of Oslo, P.O.Box 1066 Blindern, 0316 Norway \\ ${ }^{2}$ Geo-Ecological research group (GEco), Natural History Museum, University of Oslo, P.O. Box 1172 Blindern, 0318 \\ Oslo, Norway \\ ${ }^{3}$ Norwegian Institute for Water Research, Gaustadalléen 21, 0349 Oslo, Norway
}

\begin{abstract}
The biological reason for a species' presence under given environmental conditions is that the species possesses traits that make establishment and survival, usually also reproduction, possible under these conditions. Biological traits analysis (BTA), when coupled with environmental variables, can provide information regarding which traits are to be expected for a given environmental state. As such, BTA provides complementary information to multivariate analysis of community data based on species composition. In this study, BTA was conducted on a data set of sediment macrofauna collected from a temperate fjord system and related to a wide range of environmental variables. The biological traits were analysed in a multiple parallel ordination framework, which can enhance the reliability of the extracted gradient structure and evaluate the importance of weight given to abundance. Two traitclines, gradients in functional attributes of the species, were found in the study area. The first traitcline was related to bottom currents and sediment constituents while the second traitcline was related to current strength and particle deposition on the bottom. Together with a companion study of gradients in species composition (coenoclines), this study of functional features (traitclines) illustrates that the species composition may consist of taxonomically different, but functionally similar species, giving rise to strong gradients in species composition but weak gradients in trait category composition when subjected to ordination analyses.
\end{abstract}

Keywords: Ecoclines, global non-metric multidimensional scaling, indirect gradient analysis, principal component analysis, triplot, tube-building.

\section{INTRODUCTION}

Understanding the response of benthic communities to basic environmental conditions is crucial, both for practical management and conservation purposes and for understanding community change. Marine benthic communities are highly complex and respond to a wide range of ecologically structuring processes that operate on different spatial scales [1-3]. There is no lack of studies reporting how marine benthic communities are structured by environmental variation [e.g., 4-8]. However, while the mechanisms by which each of these structuring processes influence the species are generally quite well known, marine benthic ecology lacks tradition for a unified approach by which gradients in species composition (i.e., coenoclines, which are axes of unconstrained ordination methods) [9] are related to intercorrelated environmental gradients (i.e., environmental complex-gradients) [9, 10]. Such identifyication and interpretation of the co-variation of coenoclines and environmental complex-gradients are important for

*Address correspondence to this author at the Marine Biology Program, Department of Biosciences, University of Oslo, P.O.Box 1066 Blindern, 0316 Norway; E-mail: thijs.vanson@runbox.com generating new hypotheses that can be addressed both hypothetico-deductively and inductively in future studies.

The biological reason for a species' presence under given environmental conditions is that the species possesses traits that make establishment and survival, usually also reproduction, possible under these conditions [11]. Identification of traits that can be related to environmental complex-gradients may therefore assist the understanding of ecosystem functioning by providing a link between species composition and underlying structuring processes. One approach to describe and analyse traits is referred to as Biological Traits Analysis (BTA), which encompasses routines to express functional features quantitatively for analysis of patterns by numerical methods. Biological traits analysis is based on habitat templet theory [12-14], and the method was first applied to a marine benthic system by Bremner et al. [15]. Since then, the composition of traits has been related to habitats $[16,17]$, structuring processes $[18$, 19], mesh size used in sampling [20], and ecological condition [19].

Biological traits analysis offers a direct way to address the functioning of communities and ecosystems, complementary to analyses of species-environment relationships. Traditionally, community functioning has been 


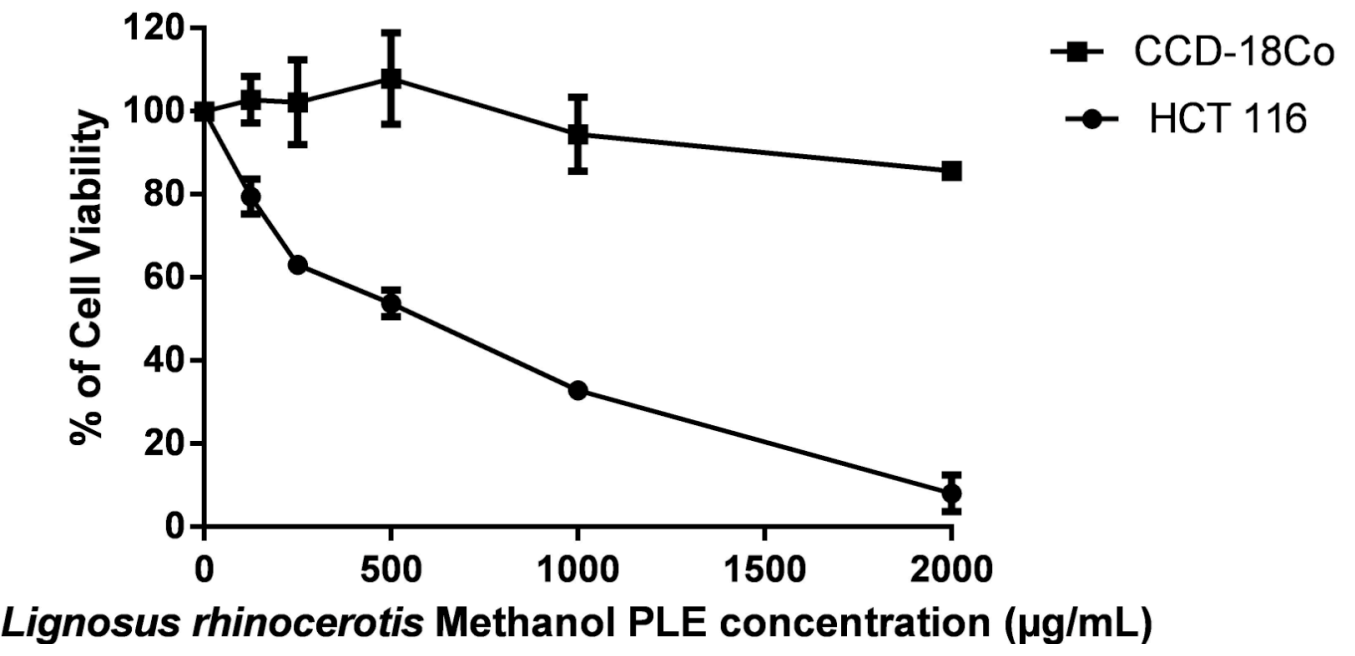

Fig. (1). Map showing the geographic location of the study area. The study area is located at the square with the black outline.

described by differences in a few features, such as feeding strategies [21] and sediment reworking ability [22, 23]. Biological traits analysis, however, dig deeper into functional properties of species and may take into account all recognisable traits, e.g., related to activity, size, shape, lifehistory characteristics (in addition to feeding strategy), and reproduction [15, 19]. As such, BTA can provide deep insights into which functional features are important in relation to the environmental conditions.

Biological traits analysis is still in its infancy and the method is still under development [24]. Presently several databases with information about traits exist, but the species included and principles used for description of trait features differ from database to database. Furthermore, trait databases are still not complete: information on one or more traits may lack for several species. This incurs loss of information when species-in-samples data are converted to trait importance-insamples data.

The aims of this study are: (1) to conduct a BTA by application of the Multiple Parallel Ordination framework [25] on a marine soft-benthic data set of macrofauna collected in a temperate fjord system; (2) to identify gradients in traits, i.e., traitclines; and (3) to relate traitclines to environmental complex-gradients and ecologically structuring processes. The aims are accomplished by using a species-by-site matrix of sediment macrofauna from the inner Oslofjord, Norway. Gradients in traits composition and environmental complex-gradients were identified by indirect gradient analysis. In multiple parallel ordination a series of data sets with different weights given to abundance are subjected to parallel analyses using two or more ordination techniques. The species data have previously been analysed for gradients in species composition (coenoclines) and their relationship with environmental complex-gradients by van Son et al. (in process).

\section{METHODS}

Study area and location of sites. The study area covering $1.05 \mathrm{~km}^{2}$ was located in the Vestfjord, inner Oslofjord (UTM32 bounding coordinates; NW corner: 6631500, 584725; SE corner: 6630500, 585775; see Fig. 1). Sampling sites were allocated according to geomorphological features using a Guided Stratified
Sampling Strategy (GSSS). The GSSS is based on a modified algorithm by Lundblad et al. [26] that classifies the seabed into geomorphological features by using a fine-scaled and a broad-scaled bathymetric position index (BPI) and slope as input variables. In addition, mean depth was used to classify certain features into their shallow and deep representations. In this study, six geomorphological features, depression, crest, shallow slope, shallow flat, deep slope, and deep flat were identified and mapped. A total of 28 sample sites were positioned by restricted random placement within each geomorphological feature, using the GSSS (Fig. 2). This procedure ensured that all six geomorphological features were about equally well represented $(3-6$ sites per geomorphological feature) among the selected sites. Geomorphological features covering larger proportions of the total study area were sampled more than features covering less of the total area.

Faunal samples. During March and April 2009, macrofauna was collected at the 28 sites from R/V Trygve Braarud by taking four van Veen grab $\left(0.1 \mathrm{~m}^{2}\right)$ samples at each site. Each sample was sieved through $5 \mathrm{~mm}$ and $1 \mathrm{~mm}$ sieves while still on board the research vessel. The remaining sediment and fauna were fixed in ethanol and stained using Rose Bengal. In the laboratory, the sediment was washed out and the fauna was sorted into the main taxonomic groups and conserved in $70 \%$ ethanol. For this study, all polychaetes, molluscs and echinoderms were identified to the species level or the lowest taxon possible and the number of individuals of each taxon counted. A total of 122 species were identified. The $122 \times 28$ species-by-site matrix formed the basis for the analyses in this study.

Biological traits. We used the traits database of the Norwegian Institute of Water Research (NIVA), presented in Oug et al. [19], to perform BTA on the recorded fauna (Table 1). Of the 122 species identified, 81 were represented in the traits database with a total of 13 traits with 55 trait categories (or modalities). These species and traits were used for the analyses. The majority of species not included in the traits analyses were represented by few specimens in our dataset. Five traits, Adult mobility (AM), Body form (BF), Degree of attachment (DA), Normal adult size (NS), and Sediment dwelling depth (SD) had complete information from all these 81 species, while two traits, Adult life habit 


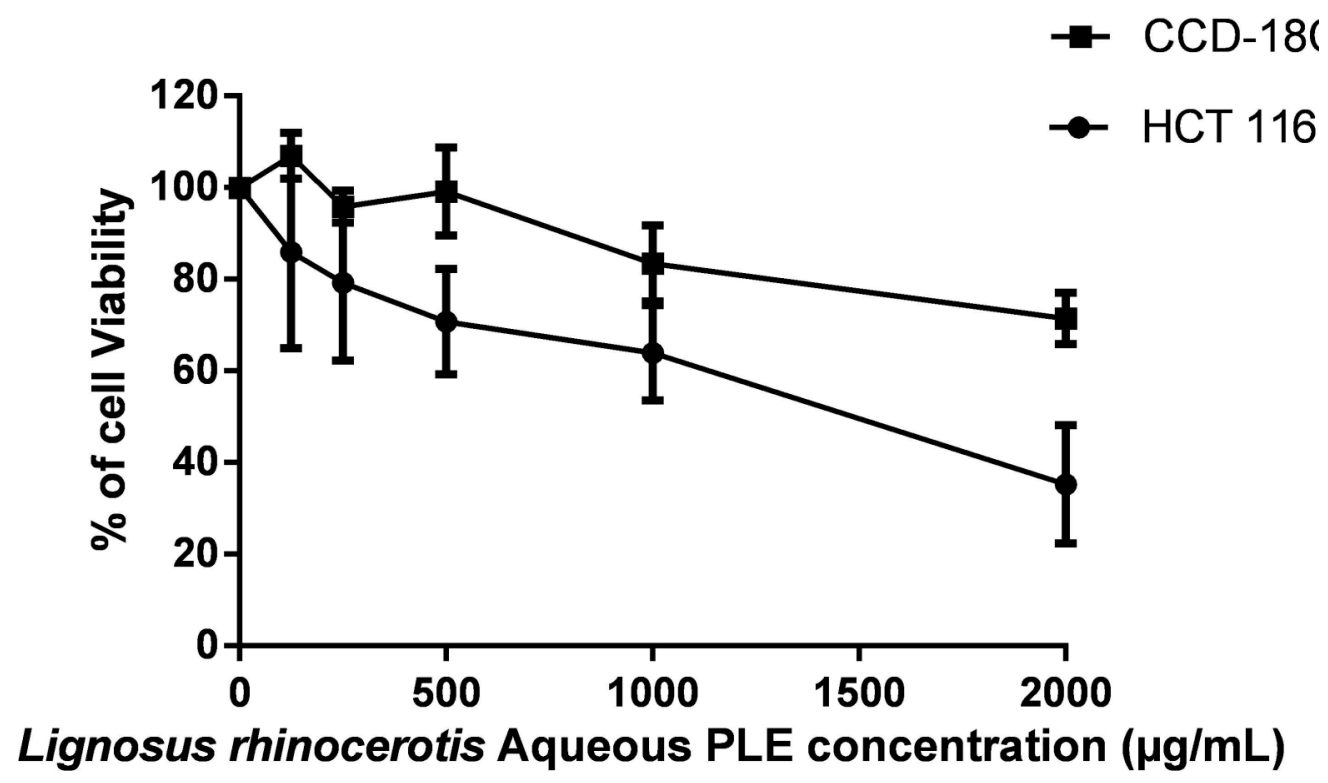

Fig. (2). Map of geomorphological features and site locations of the study area. Axes are scaled in UTM 32, WGS84 coordinates. C = Crest; D = Depression; DF = Deep Flat; DS = Deep Slope; SF = Shallow Flat; SS = Shallow Slope.

$(\mathrm{AH})$ and Feeding habit $(\mathrm{FH})$, lacked information for two species only (trait-information completeness 97.5\%). For the remaining traits, the range of trait-information completeness was between 23.5 and $72.8 \%$.

The affinity of each species for each trait category was scored by a fuzzy coding procedure [27], which allowed each species to have some degree of affinity for several categories within a trait. The affinity of a species for a particular trait category was scored on an ordinal 0-3 scale on which 0 represented no affinity and 3 represented the highest affinity. Further information about how the species were coded can be found in Oug et al. [19].

Data analysis. For each species, affinity scores for trait categories within each trait were standardised to sum $=1$. In cases of missing information, the average category-affinity score for the trait, calculated by use of all species for which information about this trait was available, was used. This was done in order not to discard potentially important information $[15,27]$. The $81 \times 56$ species-by-trait category matrix was then used for further analysis.

The analyses were performed in steps. First, the speciesby-trait category matrix was multiplied with the (transposed) species (abundance)-by-site matrix to obtain a matrix of 'abundances' for each trait category in each site [the trait category (abundance)-by-site matrix]. Several trait categoryby-site matrices were obtained by parallel use of multiple abundance ranges, i.e., with different weights given to abundance in the species-by-site matrix. The weights were calculated from the abundance range $R$, the ratio of the maximum and the minimum value for recorded presence of any species [28], which is an expression of the weight given to abundance vs. mere presence. $\mathrm{R}$ was varied by using power-function weighting [29], by which the weighted abundance of species $i$ in site $j, y_{i j}$, is obtained from the original abundance $x_{i j}$ by the equation

$y_{i j}=x_{i j}^{\frac{\log R}{\log A}}$ where $R$ is the range of the new abundance scale and $A$ is the range of the original abundance scale. We obtained speciesby-site matrices for six abundance weights: $\mathrm{R}=1$ ( $\mathrm{R} 1$, presence/absence, no weight given to abundance), the $\log _{4^{-}}$ series (R4, R16, R64, R256), and R = Rmax (raw abundance, the strongest weight given to abundance), which in this material was 784.8 .

The resulting six matrices of trait category (abundance)by-site were standardised so that the sum of abundances within each trait within each site equalled 1. By this standardisation, focus was shifted from variation in absolute values for different trait categories among sites to among-site variation in the relative importance of trait categories, i.e., to among-site variation in trait profiles.

We used R 2.15 [30] for all statistical analyses and the vegan package [31] for all multivariate analyses. The six trait-profile matrices were subjected to multiple parallel ordination (MPO; see [25]), by running Principal Components Analysis (PCA) [32,33] and Global Non-Metric Multidimensional Scaling (GNMDS) [34] in parallel. PCA was chosen rather than, e.g., Detrended Correspondence Analysis (DCA) [35,36], because pilot DCA analyses revealed that the gradients in trait-profile composition were short ( $<1$ S.D. unit). The PCA ordinations were obtained by applying the rda function to centred variables. For each of the six data sets, 100 two-dimensional GNMDS ordinations were obtained from random starting configurations using a Bray-Curtis dissimilarity matrix as input, applying the monoMDS and postMDS functions of vegan. From these 100 ordinations, the ordination with the lowest stress was selected, hence we ended up with one GNMDS result for each of the six data sets. This was done in order to minimise the risk of having a GNMDS result that has been trapped in a local minima in the internal iteration process of each run. The monoMDS function was run with the following arguments: threshold $=0.8$, weakties $=$ TRUE, scaling $=$ TRUE, maxit $=500, \operatorname{smin}=1 \mathrm{e}-7$, and sfgrmin $=1 \mathrm{e}-7$. To center and rotate the raw GNMDS axes to principal 
Table 1. Traits recorded for Polychaetes, Molluscs and Echinoderms in the Study Area, Listed in Alphabetic Order, with Trait Categories and Trait Completeness (\%). Trait Completeness is Expressed as the Proportion of all recorded Species for which Information is Available for the Trait in Question

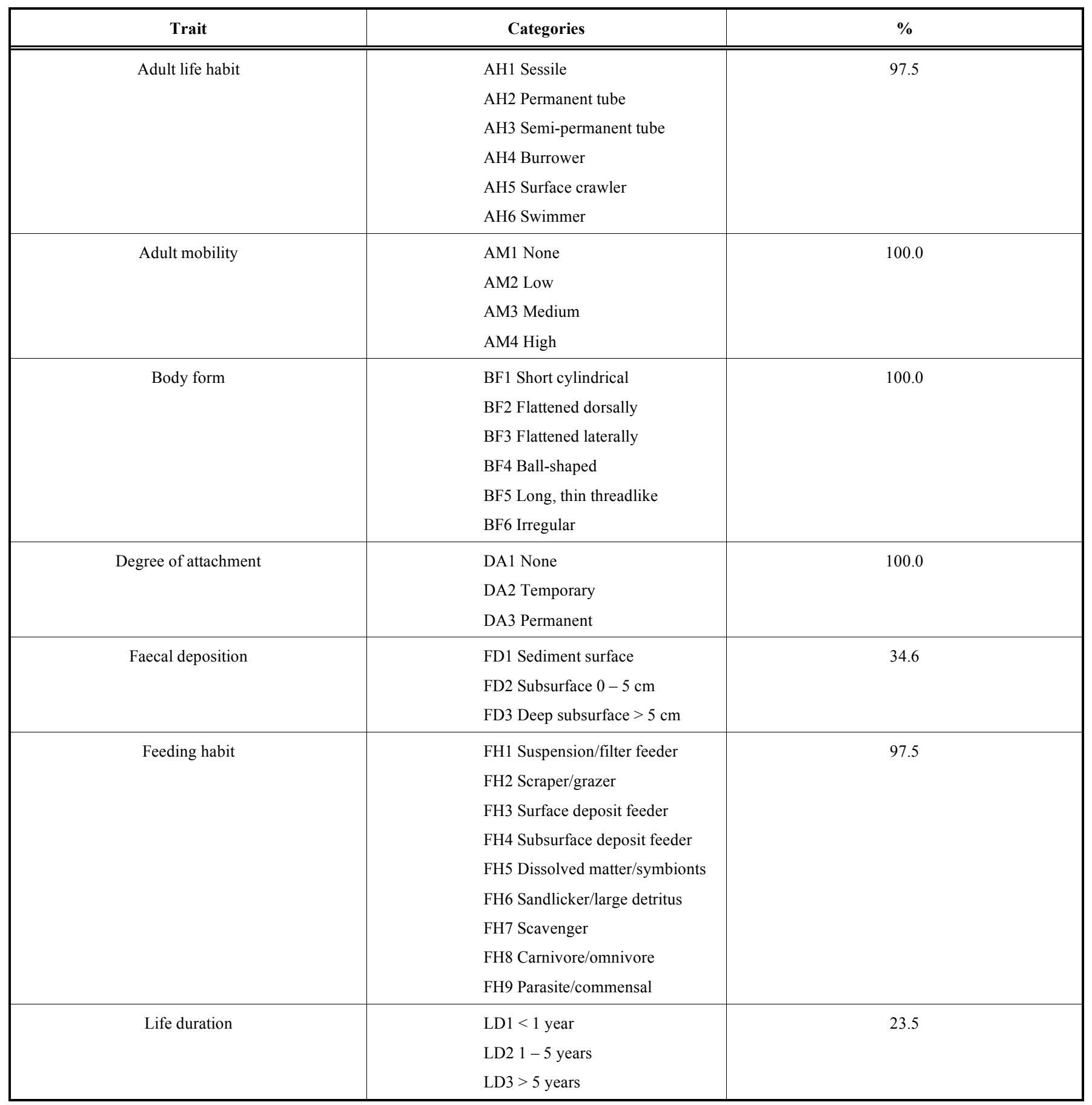

components, and to re-scale them in half-change (H.C.) units, the arguments $\mathrm{pc}=\mathrm{TRUE}$, center $=$ TRUE, and halfchange $=$ TRUE were used in the postMDS function. Subsequently, the degree of congruence between parallel PCA and GNMDS ordinations was assessed by means of Procrustes analysis [34, 37] and Kendall's rank correlations between corresponding first and second PCA and GNMDS axes.

Explanatory variables. Twenty-three environmental variables were recorded at each of the 28 sites (Table 2). These include: (1) variables that characterise the seabed features, among others depth, current regime, sediment composition, sediment structure and organic content; (2) distance from a wastewater treatment plant (VEAS: tertiary treatment for organic matter and nutrients); (3) several terrain variables derived from a digital elevation model (DEM); and (4) variables derived from a current model provided by NIVA (A. Staalstrøm, unpublished observations). In addition, the first two axes of a DCA ordination of the $122 \times 28$ species-by-site matrix were included in order to assist the interpretation of complexgradients in view of the gradients in species composition. All 
Table 2. Environmental Variables, Grouped by Type of Variable, with a Description, their Range, Mean, and Standard Deviation

\begin{tabular}{|c|c|c|c|}
\hline Variable & Description & Range & Mean (sd) \\
\hline \multicolumn{4}{|c|}{ DEM derived } \\
\hline Aspen & Eastness component of aspect & $-1.00-1.00$ & $0.10(0.73)$ \\
\hline Aspnn & Northness component of aspect & $-0.96-0.92$ & $-0.35(0.60)$ \\
\hline BPI & Bathymetric position index & $-1.52-1.34$ & $-0.06(0.70)$ \\
\hline Depth $[\mathrm{m}]$ & Depth derived from DEM & $35.8-93.2$ & $58.6(15.6)$ \\
\hline Maxcurv & Maximum curvature of the seabed (in any direction) & $-0.011-0.042$ & $0.005(0.011)$ \\
\hline Slope [deg] & The slope of the seabed & $0.3-19.8$ & $6.7(5.5)$ \\
\hline \multicolumn{4}{|c|}{ Current model } \\
\hline Botmax $[\mathrm{m} / \mathrm{s}]$ & Maximum current speed at the bottom & $0.026-0.077$ & $0.049(0.011)$ \\
\hline CurrDAbot & The rate of instantaneous change of max bottom current & $-1.71 \mathrm{e}-3-1.18 \mathrm{e}-3$ & $1.96 \mathrm{e}-6(5.63 \mathrm{e}-4)$ \\
\hline CurrDAsur & The rate of instantaneous change of max surface current & $-1.18 \mathrm{e}-3-3.61 \mathrm{e}-4$ & $-1.92 e-4(3.61 e-4)$ \\
\hline Dirboten & Eastness component of the direction of the bottom current & $-1.00-0.97$ & $-0.47(0.64)$ \\
\hline Dirbotnn & Northness component of the direction of the bottom current & $-1.00-1.00$ & $0.24(0.58)$ \\
\hline Surmax $[\mathrm{m} / \mathrm{s}]$ & Maximum current speed at the ocean surface & $0.061-0.091$ & $0.068(0.007)$ \\
\hline \multicolumn{4}{|c|}{ Particle-size } \\
\hline Kurt & Kurtosis of the sediment particle distribution & $0.70-1.31$ & $0.94(0.15)$ \\
\hline Med $[\mu \mathrm{m}]$ & Median sediment particle-size & $28.0-944.9$ & $97.1(179.7)$ \\
\hline Mudcont [\%] & The silt-clay fraction of the sediment & $8.4-77.2$ & $55.6(16.2)$ \\
\hline Skew & Skewness of the sediment particle-size distribution & $-0.78-0.36$ & $0.09(0.25)$ \\
\hline Sort & Sorting of the sediment particle-size distribution & $4.2-8.6$ & $5.8(1.0)$ \\
\hline \multicolumn{4}{|c|}{ Other variables } \\
\hline $\mathrm{BMD}[\mathrm{cm}]$ & Biogenic mixing depth derived from sediment profile images & $0.0-3.1$ & $1.7(0.8)$ \\
\hline Pendep $[\mathrm{cm}]$ & Penetration depth of SPI - a proxy for sediment shear strength & $0.0-19.4$ & $12.2(5.6)$ \\
\hline TOC $[\%]$ & Percentage of total organic carbon & $1.7-5.6$ & $3.8(0.7)$ \\
\hline $\mathrm{TN}[\%]$ & Percentage of total organic nitrogen & $0.12-0.63$ & $0.34(0.09)$ \\
\hline $\mathrm{CN}$ & Carbon-to-Nitrogen-ratio & $7.9-19.3$ & $11.5(2.0)$ \\
\hline VEAS [m] & Distance from effluent of VEAS waste water treatment plant & $1143-2120$ & $1640(318)$ \\
\hline
\end{tabular}

explanatory variables were zero-skewness transformed [38] and ranged to a $0-1$ scale. The explanatory variables were passively fitted to the first two ordination axes of the selected data sets (the qualitative data set [R1], an intermediate data set, and the raw data set [Rmax]) by application of the envfit function. This function applies a bivariate linear regression to find vectors representing the direction of the most rapid increase of the explanatory variable in question in the ordination diagram [31].

\section{RESULTS}

The fauna. The fauna was dominated by small, sediment-living species, typically known to be found in temperate fjords and coastal waters. The number of species per site varied from 30 to 59 with a mean of $41.5(\mathrm{sd}=7.2)$ and the total abundances from 500 to 2500 ind. $\mathrm{m}^{-2}$. More than 20 species were found at $80 \%$ (22) or more of the 28 sites. The most abundant species were the polychaetes Spiophanes kroeyeri (28 sites, mean abundance 213 ind. $\mathrm{m}^{-2}$ , sd = 84.7), Pseudopolydora paucibranchiata $(19 ; 98$ ind. $\left.\mathrm{m}^{-2}, \mathrm{sd}=107.1\right)$, Heteromastus filiformis $\left(27 ; 54\right.$ ind. $\mathrm{m}^{-2}, \mathrm{sd}$ $=41.1)$ and Chaetozone setosa $\left(26 ; 51\right.$ ind. $\left.\mathrm{m}^{-2}, \mathrm{sd}=27.7\right)$ and the bivalves Ennucula tenuis $\left(26 ; 213\right.$ ind. $\mathrm{m}^{-2}$, sd = 58.9), Thyasira equalis $\left(27 ; 43\right.$ ind. $\mathrm{m}^{-2}$, $\left.\mathrm{sd}=15.3\right)$ and Thyasira sarsi $\left(25 ; 20\right.$ ind. $\left.\mathrm{m}^{-2}, \mathrm{sd}=6.2\right)$. The most common echinoderms were the brittle stars Ophiura affinis $(18 ; 14$ ind $\left.\mathrm{m}^{-2}, \mathrm{sd}=5.4\right)$ and Amphiura filiformis $\left(13 ; 8\right.$ ind. $\mathrm{m}^{-2}, \mathrm{sd}$ $=2.3$ ).

Relative importance of trait categories. Four of the 59 trait categories listed for the 13 selected traits in the traits database were not represented by any species observed in our data set (Adult life habit categories, AH1: sessile, AH6: 

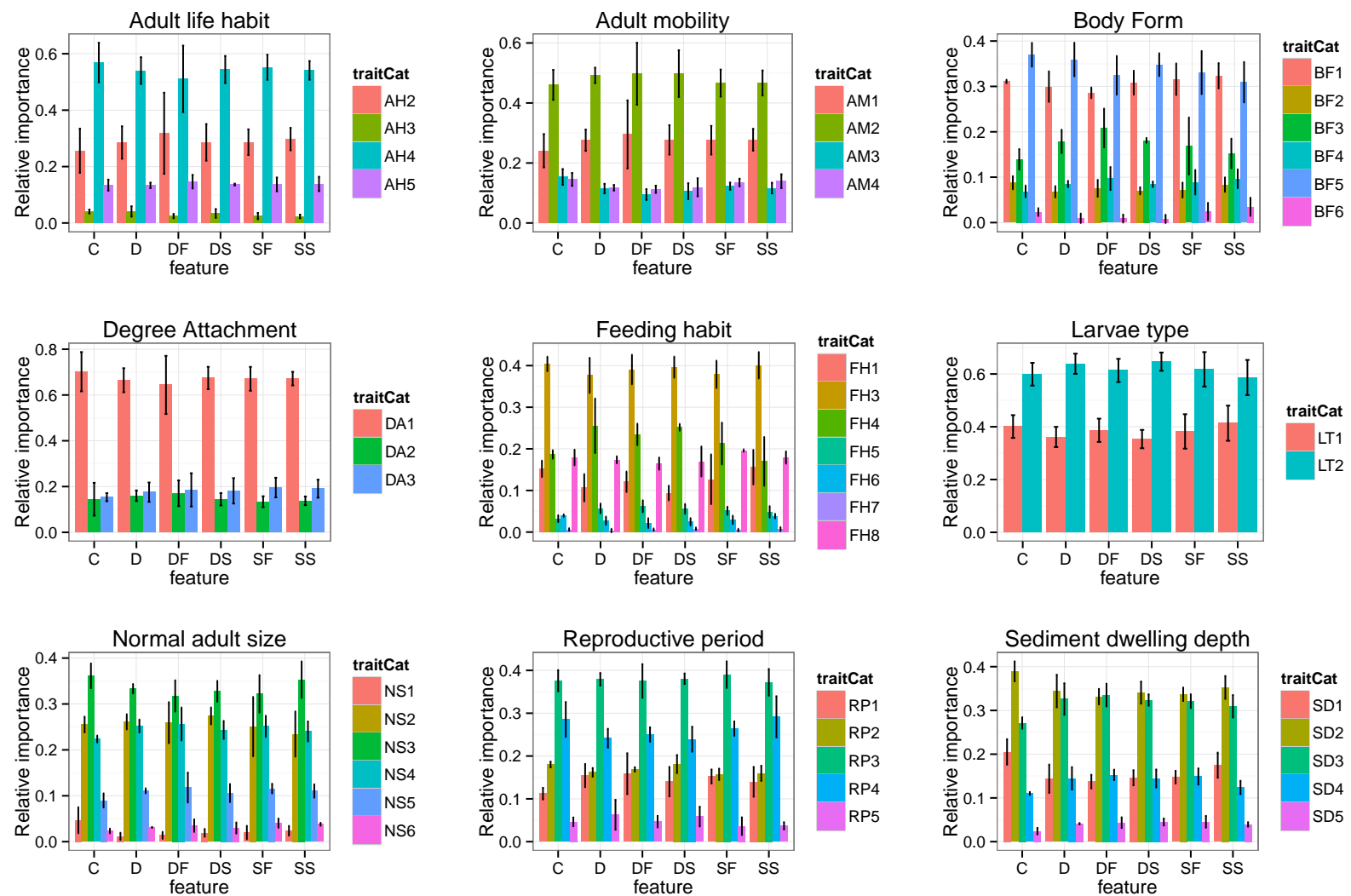

Fig. (3). Barplots showing the relative importance of trait categories within each broad-scaled geomorphological feature. The relative importance is calculated as the mean over all sites for each trait category. Error bars indicate mean \pm 1 SD.

swimmer; and Feeding habit categories, FH2: scraper/grazer, and FH9: parasite/commensal), leaving 52 trait categories with positive abundance values for at least one site in the trait category-by-site matrices. The most common trait categories in our data set were (Fig. 3): burrower (AH4) and permanent tube (AH2) as Adult life habit; low (AM2) or no (AM1) Adult mobility; long, thin threadlike (BF5) and short cylindrical (BF1) Body form; No (DA1) Degree of attachment; surface (FH3) and subsurface (FH4) deposit Feeding habit; non-feeding (LT2) Larvae type; Normal adult size between 0.5 and $6 \mathrm{~cm}$ (NS2-4); Reproductive period during summer (RP3) and during autumn (RP4); and Sediment dwelling depth between 0 and $5 \mathrm{~cm}$ (SD2-3).

The relative importance of trait categories (trait profiles) in general did not vary much across geomorphological features (Fig. 3). For two traits, Feeding habit and Sediment dwelling depth, some differences in the relative importance of trait categories were found between crest and shallow slope sites on one hand and sites from all other features on the other hand. For Feeding habit, the relative importance of suspension feeding (FH1) was higher in crest and shallow slope sites, while for subsurface deposit feeding (FH4) the converse was true, compared to all other features. Crest and shallow slope sites in general had a higher relative abundance of surface-dwelling species (SD1 and SD2) than other features.

Comparisons between PCA and GNMDS ordinations. Measures of congruence between PCA and GNMDS ordinations based on trait profiles with different abundance ranges $(\mathrm{R})$ showed that the ordination methods extracted very similar, close to identical, two-dimensional representations of trait-profile structure (Table 3). Parallel ordinations (i.e., PCA and GNMDS ordinations based on trait profiles with the same abundance range had Procrustes correlations between 0.83 , for $\mathrm{R} 4$, and 0.98 , for Rmax. Kendall tau correlations between corresponding first axes of PCA and GNMDS ranged between 0.83 (R4) and 0.94 (R1). For the corresponding second axes, tau values ranged between 0.56 (R1) and 0.83 (R16) with the exception of ordinations using R4, which had a tau value of 0.25 . For

Table 3. Procrustes Correlation Coefficients (r) Between Parallel PCA and GNMDS Ordinations, and Kendall's tau Correlations ( $\tau 1$ and $\tau 2)$ Between Corresponding Axes, for each of the Six Weights given to Trait-Category Abundance (R1 - Rmax). The Abundance Ranges Selected to Represent no, Intermediate, and Strong Weights given to Abundance (see Text for Explanation of Criteria) are Indicated by Bold-Face Numbers. Rmax $=784.8$

\begin{tabular}{|c|c|c|c|}
\hline Range & $\mathbf{r}$ & $\boldsymbol{\tau} \mathbf{1}$ & $\boldsymbol{\tau} \mathbf{2}$ \\
\hline \hline R1 (qual) & 0.939 & 0.937 & 0.555 \\
\hline R4 & 0.827 & 0.825 & 0.254 \\
\hline R16 & 0.969 & 0.878 & 0.825 \\
\hline R64 & 0.964 & 0.931 & 0.762 \\
\hline R256 & 0.964 & 0.905 & 0.608 \\
\hline Rmax (raw) & 0.984 & 0.905 & 0.714 \\
\hline
\end{tabular}



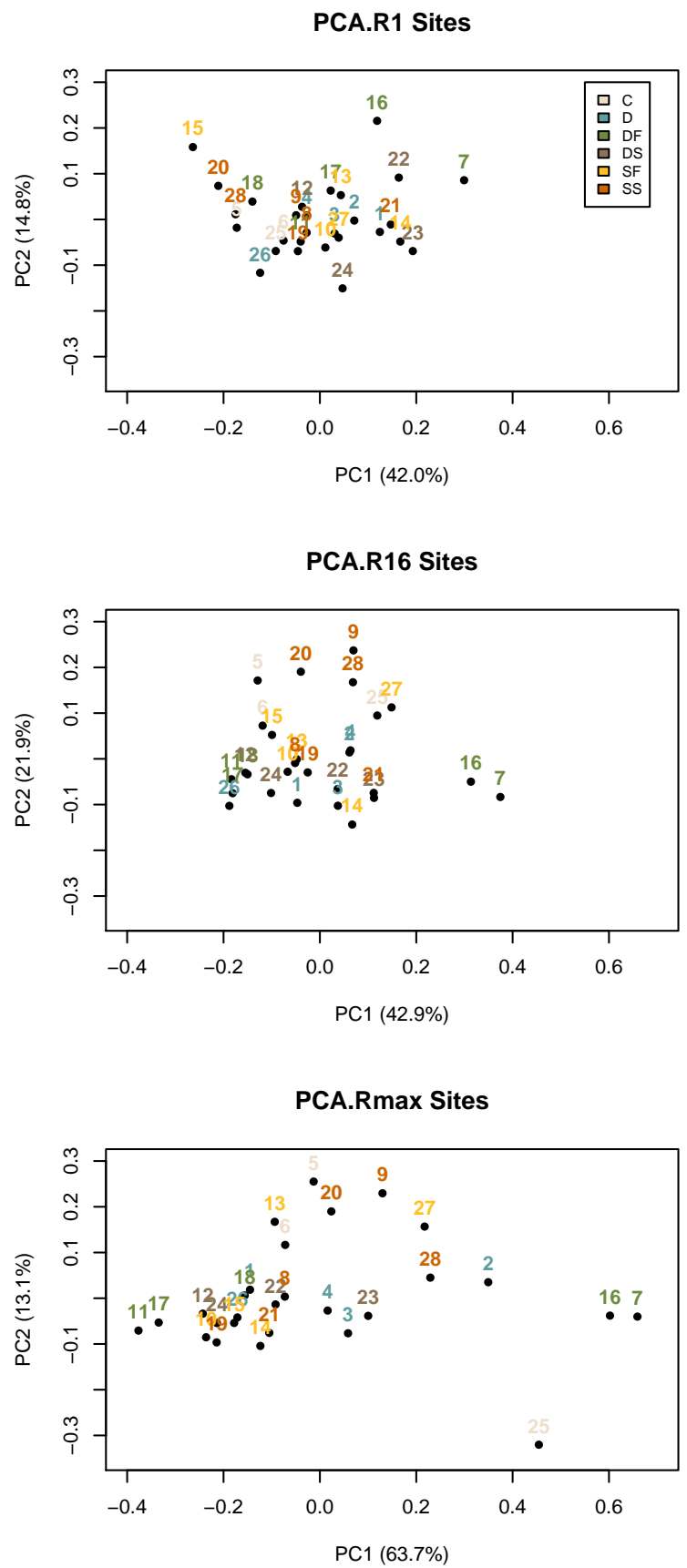

Fig. (4). PCA site diagrams for three abundance ranges: a) presence/absence (qualitative data) [R1], b) intermediate [R16] and c) strong $[R \max ]$ weight given to abundance. Positions of sites 128, with affiliation to broad-scaled geomorphological feature indicated by the color of the dot, are shown. $\mathrm{C}=$ Crest; $\mathrm{D}=$ Depression; DF = Deep Flat; DS = Deep Slope; $\mathrm{SF}=$ Shallow Flat; $\mathrm{SS}=$ Shallow Slope.

further analyses, the PCA ordination diagrams were used because PCA also provides scores for the variables in the analyses, i.e., trait categories. Interpretation of ordination axes was primarily based on the PCA ordination diagram for the intermediate weighting R16 of abundance because the Procrustes correlation between PCA and GNMDS ordinations of intermediate weighting was maximised for this value of $\mathrm{R}$. In addition, ordination diagrams based on no
(R1) and strong (Rmax) weight given to abundance were subjected to interpretation, in order to explore the extent to which patterns of variation in trait profiles were affected by the weight given to abundance.

Description of PCA ordination patterns of sites. The gradient lengths of all ordination axes were very short. In general the gradient lengths of PCA ordination axes increased with increasing weight given to abundance (Fig. 4). This was most clearly seen for axis 1 . No weight and intermediate weight given to abundance resulted in almost equal gradient lengths of 0.163 and 0.172 H.C. units, respectively, for the two GNMDS axes, whereas the gradient length increased substantially (to 0.613 H.C. units) when strong weight was given to abundance. The variance explained on PC1 increased with increasing weight given to abundance. Principal component 2 had the highest variance explained for the intermediate weighting. None of the analyses indicated very clear relationships between sites and geomorphological features. For the intermediate abundance range, deep flat and depression sites were present at both ends of PC1, but most features were mixed in the middle part of the axis. On PC2, shallow surface, shallow flat and crest sites tended to occupy the positive end. This pattern was found also in the analysis with high weight on abundance, but not in the analyses based upon presence/absence data (R1). Some sites changed their relative position significantly with increasing range of the abundance scale. This was for instance the case for (1) the deep flat sites, 7 and 16, which obtained increasingly extreme, positive, PC1 scores; (2) a group of crest sites (5 and 6) which, together with shallow slope $(9,20,28)$ and shallow flat $(13,27)$ sites, moved from the centre of the ordination diagram, eventually forming a group of sites with positive PC2 scores; (3) site 25, a crest site, which first followed the sites in pattern 2, but then moved to an extreme position at negative PC2 scores; (4) the deep flat sites, 11 and 17, which moved from the centre to the opposite direction of deep flat sites 7 and 16, eventually occupying the extreme, negative, position along PC1; and (5) the shallow flat site 15, which moved from the upper left corner of the ordination diagram to become part of the central cluster of sites.

Description of gradients in trait-category composition. The trait-category scores along ordination axes were also affected by the weight given to abundance. For the intermediate abundance range, several traits exhibited clear differentiation of trait categories along the first and second axes (Fig. 5). Clear differentiation along PC1 was observed for Adult life habit (AH), Adult Mobility (AM), Normal adult size (NS) and Degree of attachment (DA). For DA, categories None, Temporary and Permanent made up a sequence from negative to positive PC1 scores, indicating stronger degree of attachment towards the positive end of $\mathrm{PC} 1$. Also the size of individuals increased with increasing $\mathrm{PC} 1$. Clear differentiation along $\mathrm{PC} 2$ was observed for Feeding habit (FH), Reproductive period (RP), Larvae type (LT), and Sediment dwelling depth (SD). For FH, a shift from suspension feeding via surface deposit feeding to subsurface deposit feeding was observed when moving from high to low PC2 scores, accompanied by a shift from late to early reproduction. With increasing weight given to abundance, less clear differentiation was observed for 

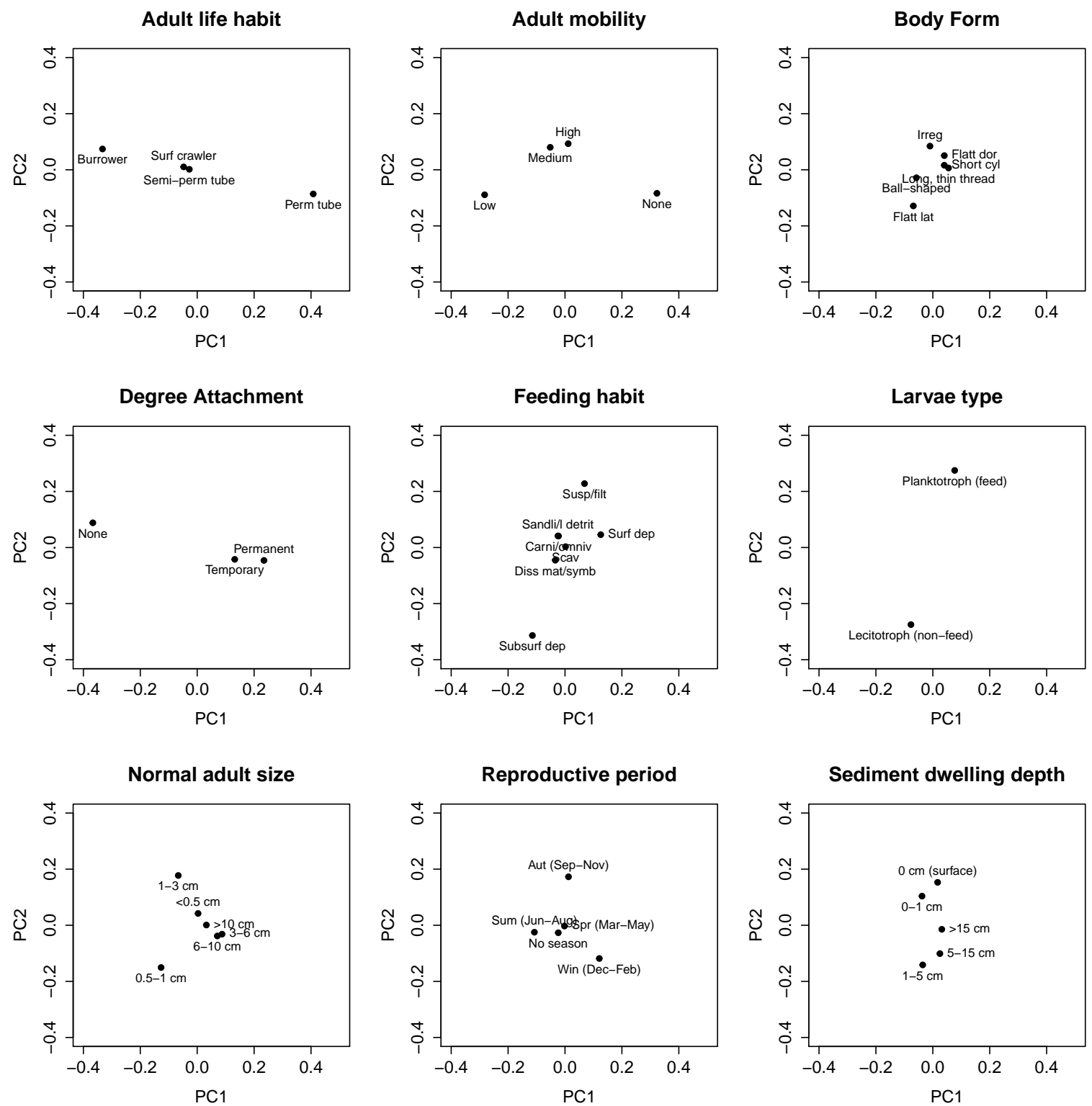

Fig. (5). PCA trait-category diagram for the intermediate weight given to abundance (R16). The points for each trait category represent arrowheads for vectors from the centroid, pointing in the direction of the most rapid increase in the relative abundance of this trait category Trait category names are abbreviated in accordance with Table $\mathbf{1}$.

Table 4. Kendall's rank correlation coefficients $(\tau)$ between PCA axes obtained with no (R1), intermediate (R16) and strong (Rmax) weight given to trait-category abundance, and explanatory variables. Bold-face values represent $|\tau| \geq 0.225$, which corresponds to a p-value of approximately 0.10 in tests of the hypothesis that $\tau=0(n=28)$. DCAx.R32 represent site scores for the two first axes of a DCA ordination of the species-abundance matrix of the full data set with 122 species, using an abundance range of $R=32$

\begin{tabular}{|c|c|c|c|c|c|c|}
\hline & & PC1 & & & PC2 & \\
\hline Aspen & 0.000 & 0.169 & 0.164 & 0.286 & 0.201 & 0.132 \\
\hline Aspnn & -0.090 & 0.048 & 0.106 & -0.090 & 0.228 & 0.011 \\
\hline
\end{tabular}


Table 4. contd...

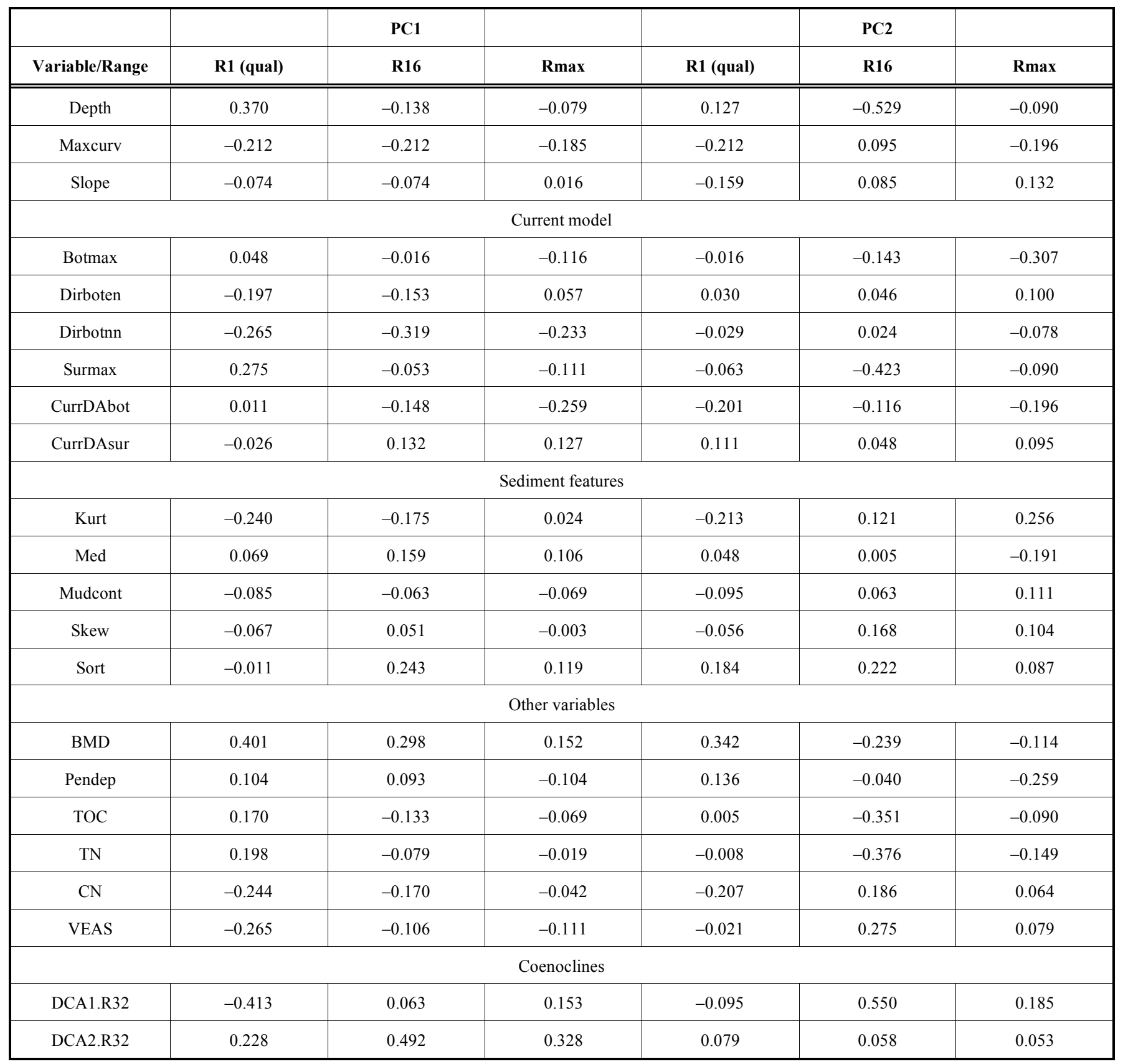

Reproductive period (RP) and Reproductive technique (RT), whereas small changes were observed for Adult life habit $(\mathrm{AH})$, mobility (AM) and Feeding habit (FH, see Fig. 6).

Relationship between ordination axes and environmental variables. As a consequence of the changes in the ordination axes with different weights given to abundance, the relationship between axes and environmental variables was also affected (Fig. 6). The largest number of correlated environmental variables was found for the PCA ordination obtained for intermediate abundance weights (R16), for which also the highest individual correlation coefficient between an ordination axis and explanatory variables was found (Table 4). Ordination axes obtained for presence/ absence data (R1) were also correlated with a relatively large number of variables, but both the number and the magnitude of the correlations were lower than for the ordination based on R16. Rather few correlations of low magnitude were found between PCA axes and variables when strong weight was given to abundance ( $R \max$ ).

Due to the large differences in ordination results in response to changes of the abundance range, only one environmental variable, viz. the northing component of the direction of the bottom current (Dirbotnn), was consistently correlated with a PCA axis (PC1) irrespective of abundance range (see Table 4). Other variables correlated to $\mathrm{PC} 1$ at intermediate abundance ranges were biological mixing depth (BMD) and sorting. Depth was the variable most strongly correlated with PC2 for the intermediate abundance range followed by maximum surface current (Surmax), total nitrogen (TN), and total organic carbon (TOC). Both axes 
were also correlated to DCA axes extracted in analyses of gradients in species composition. PC1 was consistently related to the second axis (DCA2.R32) with intermediate weight on abundance, whereas PC2 were related to the first axis (DCA1.R32) in the same analysis.

\section{DISCUSSION}

The gradient structure of sites based upon trait-category composition (i.e., the existence and composition of traitclines in the data set) as well as the relationship between traitclines and environmental complex-gradients, is strongly affected by the weight given to abundance. The generally short gradient lengths do, however, indicate that the variation in trait-category composition between sites in the study area is small and taking place mainly within geomorphological features. Lack of a strong gradient structure may increase the sensitivity of the gradient structure to variation in abundance range. When maximum weight is given to abundance, a few species that dominate in certain sites extensively affect the gradient structure. On the other hand, trait features and environmental gradients that correlate across analyses with low and high weights then reveal relationships that are shown both in the distribution of all species and in the abundance pattern of the few most dominating forms. As such, the approach using parallel ordinations with wide abundance ranges gives considerable strength to the search for basic functional features of the species communities.

Interpretation of gradients in trait-category composition (traitclines): The traitcline related to PC1. All first PCs, regardless of weight attributed to species abundance, separate sites based upon abundance of categories of traits related to species habit and mobility: burrower (AH4), no attachment (DA1) and low mobility (AM2) occupy positions at the negative end of PC1, while permanent tube (AH2), permanent attachment (DA3) [temporary attachment (DA2) when raw abundance is used] and no mobility (AM1) occupy extreme positions at the positive end of this axis. Permanent tube, permanent attachment and lack of mobility are all expressions of the habit of constructing tubes and staying in one place. We therefore interpret the first axis as representing a gradient (traitcline) from higher relative importance of free-living species, via high importance of semi-permanent, temporarily attached tube builders, to higher relative importance of tubeconstructing, stationary species.

Construction of tubes is an important activity, also in an ecological context, as tubes are large and solid structural elements in the sediments which otherwise often consist of small particles. Several of the tubes made by polychaetes are moulded together by secretion which essentially glues sediment particles together [40, 41]. The environment for associated fauna in tube-rich sites, may therefore differ considerably from sediments with similar grain-size structure, but without tubes. Furthermore, tubes that emerge from the sediment surface form a lattice that generates current shear forces in the immediate vicinity of the sediment surface which may, in turn, enhance particle deposition [40, 42, 43]. In all ordination analyses, regardless of abundance weighting and in particular at raw abundance, surface deposit feeding (FH3) and large size (NS4) are affiliated with tube-construction, indicating that these traits
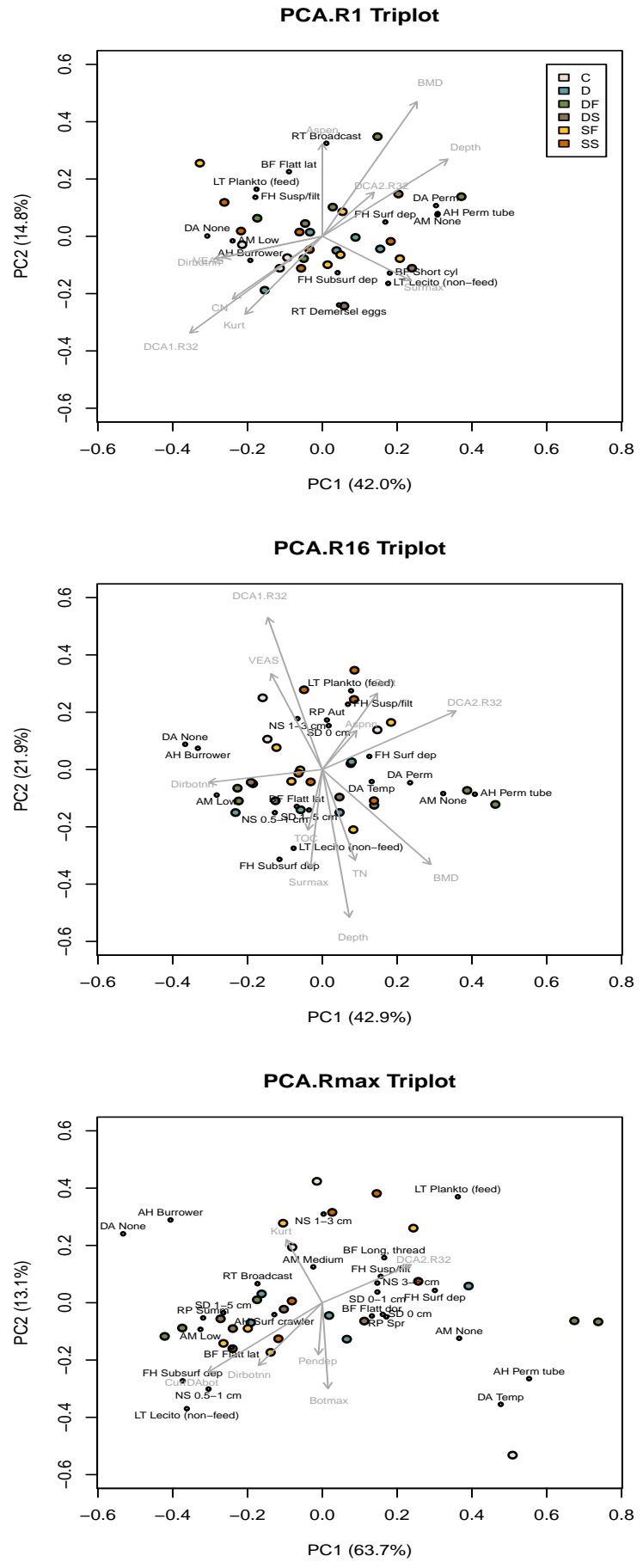

Fig. (6). PCA triplots showing site locations, trait categories, and vectorfitted environmental variables for a) presence/absence (qualitative data) [R1], b) intermediate [R16] and c) strong [Rmax] weight given to abundance. Trait categories with loadings with absolute value $>0.125$ on one or both PCA axes are shown. Environmental variables with $|\tau| \geq 0.225$ were fitted to the PCs by the envfit() function in vegan. The length of environmental variable vectors indicate the strength of their correlation with PCA axes. Trait category names are abbreviated in accordance with Table $\mathbf{1 .}$ Environmental variables are described in Table 2. DCA1/2.R32 represent site scores for the two first axes of a DCA ordination of the species composition of the full data set (122 species), using abundance range $\mathrm{R}=32$. Geomorphological features $=$ Crest; $\mathrm{D}=$ Depression; DF = Deep Flat; DS = Deep Slope; $\mathrm{SF}=$ Shallow Flat; $\mathrm{SS}=$ Shallow Slope. 
that are not forming part of the traitcline described above, may also show variation in trait-category distribution along this gradient.

The northing component of the direction of the bottom current (Dirbotnn) is the single environmental variable best correlated with PC1. An animation of the bottom current model reveals that the strongest bottom current in the study area flows from the north-northeast and occurs when the tide is flowing out of the fjord. Bottom currents are considered generally important for marine benthic fauna, especially in relation to the erodability [44] of the sediment and for transportation of food [45]. Tube-building sessile species are totally dependent on food being brought to their living place. We therefore hypothesise that bottom currents are structurally important for the variation in composition of trait categories. Interestingly, and providing support for this hypothesis, is the high correlation of PC1 with the second axis of the DCA ordination of the species abundances (DCA2.R32). van Son et al. (in process) interpreted DCA2.R32 to be related to a complex-gradient of bottom current features. Furthermore, and also in accordance with the results of this study, they found that subsurface deposit feeders were affiliated with the negative end and surface deposit feeders were associated with the positive end of their DCA2.

Biological mixing depth (BMD) and sediment sorting (Sort) were also correlated with the first traitcline, but the relationships were weaker. Tubes may affect seabed sediments in different ways; scattered tubes may enhance local erosion, whereas high densities of tubes may lead to sediment accretion $[42,46]$. The relationship of the traitcline to sorting, i.e., increased abundance of tubes in intermediately sorted sediments (e.g., sites 7, 16, 21 and 23), may suggest that a relatively good range of particle sizes facilitates tube construction. Highly unsorted sediments (e.g., sites 5, 9, and 15) is an indication of high-energy areas where tube-construction may become less common because adequate particle sizes may be too rare. Conversely, highly sorted sediments (e.g., sites 11, 17, and 26) may not provide sufficient variation in particle size as well as particles being too small for efficient tube-building. Many tube-building species select particular objects or grain-sizes for their tubes (see e.g., [47]). We hence interpret the first axis as a traitcline related to a complex-gradient with bottom currents and sediment constituents as important contributing variables. This traitcline differentiates poorly between the geomorphological features in the study area, which is illustrated by sites from deep flats being located at both ends of the axis. However, this is not unexpected, considering that tube-living species are found over a great range of environments, from soft to mixed sediments and even at hard bottoms. This result indicates that significant biological features such as tube construction are not clearly related to geomorphological features.

Several sites show considerable shifts in positions along ordination axes relative to the bulk of sites, when the weight given to abundance is varied. In particular, the sites 16, 7, 25 and 2 move to more extreme, positive, positions along PC1 when increasing weight is given to abundance (Rmax). These sites were characterised by high abundances of the most dominant species, viz. the spionid polychaetes Spiophanes kroyeri $(16,7,2)$ and Pseudopolydora paucibr- anchiata, both of which are tube-constructing surface deposit feeders. Similarly, sites 11 and 17 move to more extreme, negative, positions along $\mathrm{PC} 1$ and 10 and 19 moves outwards to become more similar with 12, 24 and 26. These sites were characterised by high abundances of the other dominant species, the small bivalves Ennucula tenuis and Thyasira spp and the polychaetes Heteromastus filiformis and Chaetozone setosa. These are free-living (nontubebuilding), subsurface-living and mostly subsurface deposit-feeding species with low mobility. Giving high weight to abundance (dominance) in the analyses strengthens the importance attributed to tube-construction in contrast to a free-living habit as basic biological features in sediment communities.

The traitcline related to $\mathrm{PC2}$. The second $\mathrm{PC}$ separates sites based upon abundance of categories of traits such as feeding habit (FH), larval types (LT), size (NS), and sediment dwelling depth (SD): trait categories suspension feeding (FH1), planktotroph larvae (LT1), medium size (NS3), surface-living and shallow-digging forms (SD1, SD2), and highly mobile forms (AM3, AM4) occupy positions at the positive side of the axis, while subsurface deposit feeding (FH4), lecitotroph larvae (LT2), and small size (NS2) occupy positions near the negative end of the axis. In the sequence of ordinations from presence/absence data (PCA.R1) to high weight (PCA.Rmax) on abundance, Larval type and Feeding habit remain stable while the scores of several trait categories along the ordination axes change considerably. This is exemplified by the trait Reproductive technique (RT), for which the categories broadcast spawner (RT2) and demersal eggs (RT3) occupy extreme positions along PC2 in the qualitative analysis (PCA.R1), while hardly being separated in analyses with high weight given to abundance. We identify the second axis as a traitcline from surface living and shallow-digging suspension feeders with planktotrophic larvae to sediment-dwelling deeper-digging subsurface feeders with lecitotrophic larvae.

The second traitcline (PC2) is correlated with several environmental variables, the most important of which are depth and several variables more or less strongly correlated with depth, such as total nitrogen (TN), total organic carbon (TOC), and maximum current speed at the ocean surface (Surmax). Thus, deep-digging subsurface feeders with lecitotroph larvae are associated with deep sites with high input of organic matter and high ocean surface current. In contrast, surface-living and shallow-digging suspension feeders with planktotroph larvae are found at shallow depths with little retainment of organic material and low ocean surface current. The correlations of PC2 with organic carbon, nitrogen and surface currents suggest that a complexgradient related to the current regime and the supply of organic matter may explain this traitcline. Since concentrations of organic carbon and nitrogen are highly determined by particle-deposition rates, we interpret the second axis as a traitcline related to a complex-gradient with current strength and particle deposition on the bottom as important contributing variables.

Support for this interpretation also comes from the high correlation between PC2 and the first ordination axis in the DCA of species abundances (van Son et al., in process) which was interpreted as consisting of two ecoclines, one 
termed periodic physical forcing (mainly in shallow sites), the other termed periodic hypoxia (mainly in deep sites). High importance of periodic physical forcing towards crests is supported by generally coarse sediments at constituent sites with a thin flocculate layer on top, suggesting high organic input which temporarily accumulates on the bottom. Hypoxia is normally associated with high deposition rates of organic matter. Thus, the high importance of periodic hypoxia towards deeper sites was supported by high organic content at constituent sites as well as previous measurements of oxygen levels in the area documenting poor oxygen conditions during periods of stagnant water masses [48-51].

The separation of trait categories along $\mathrm{PC} 2$, showing that suspension feeding, surface living, and medium to high mobility and medium size characterise the hypothesised physical-forcing end of the gradient, supports our interpretation. Furthermore, categories such as shallowdigging subsurface deposit feeding, small size and lecitotroph larval development that characterise organically enriched environments, increase towards the other end of the gradient. Such environments typically become deficient in oxygen in extended periods of little or no water movement. Our results accord with results of Pacheco et al. [18] who demonstrate dominance of small-sized, subsurface burrowing animals in permanently hypoxic sites. Returning to our analyses again, they do not clearly answer the question if intermittent hypoxia or processes related to organic enrichment are most important for the development of particular functional traits.

Compared to the first traitcline (PC1), the second traitcline (PC2) represented by PCA ordination axes with intermediate weight given to abundance differentiates to some degree among geomorphological features. This can be observed near the positive end of PC2, where shallowbottom features (crest, shallow slopes and shallow flats) occur. Deeper-bottom geomorphological features exhibits an affiliation with the negative end of $\mathrm{PC} 2$, as expected from the high correlation between PC2 and depth. As such, it is possible that the observed traitcline in current strength and particle deposition on the bottom, can, at least partly, be predictable from the geomorphology.

\section{CONCLUSION}

Together with the companion study of gradients in species composition (coenoclines; van Son et al., in process), this study of functional features (traitclines) illustrates that the species composition in a restricted area, in which the variation along major environmental complex-gradients is limited, may consist of many taxa that are functionally similar. This gives rise to strong gradients in species composition but weak gradients in trait category composition when data are subjected to ordination analyses; i.e., considerably stronger coenoclines than traitclines. Our results for the two types of information (coenoclines and traitclines) are nevertheless consistent because the axes of both sets of ordinations are interpretable as responses to similar, though not identical, complex-gradients. The results of analyses of traits category composition throw light on which functional features are important for the composition and development of communities in the area. The BTA approach thus provides additional ecological insights into biotic systems and therefore complements the traditional analysis of species composition followed by environmental and ecological interpretation.

Two traitclines, gradients in functional attributes of the species, are found in the study area. The second traitcline, current strength and particle deposition on the bottom, represented by $\mathrm{PC} 2$, is partly correlated with geomorphological features of the seabed (this gradient agrees with established knowledge in benthic ecology; e.g., $[52,53])$. Existence of the other traitcline, bottom currents and sediment constituents, represented by $\mathrm{PC} 1$, supports a hypothesis that structural elements produced by tubebuilding species are important in an ecological context. This accords with studies on animal-sediment relationships (e.g., $[46,54])$. Tube-building macrofauna is often found in physically disturbed habitats [54] or early in the recovery after defaunation [43] and are also known to facilitate softbottom benthic succession [55]. The Oslofjord is generally influenced from municipal and industrial effluents and shows gradients in several contaminants and organic load [19,39]. It is possible that intermittent disturbance, e.g. from oxygen depletion, may occur in the study area and thus contribute to enhance tube construction as a main functional feature of the species communities.

To our knowledge, the present framework for identification of basic gradients in functional features, i.e. traitclines, and the interpretation of the traitclines in relation to environmental complex-gradients, represents a new analytical approach to the study of functioning in benthic ecosystems. The use of multiple parallel ordinations enables us to assess the reliability of the analytical results as well as providing insights into the functional features of the species assemblages in both qualitative and quantitative terms. As such, the approach has the potential to evaluate which functional features are important for variation in species communities and hence contribute to enhance our understanding of species-environment relationships and community structuring processes. The present study has particularly highlighted tube-building as an important feature in addition to more well-known attributes such as feeding strategies and sediment dwelling depth. It remains a matter for further study to assess the generality of these features for structuring processes in benthic ecosystems across different environmental conditions.

\section{CONFLICT OF INTEREST}

The authors confirm that this article content has no conflicts of interest.

\section{ACKNOWLEDGEMENTS}

The authors would like to thank Rita Amundsen and Berit Kaasa for assistance in the lab; Øystein Stokland for assistance in identifying mollusc species; Andre Staalstrøm for providing the ocean current model; the late Frode Olsgard, Bjørnar Beylich, Hasse Nilsson, Ketil Hylland, Gunhild Borgersen, Master students, and the crew of R/V Trygve Braarud for assisting in the field work; and to Norwegian Institute of Water Research (NIVA) for providing access to the SPI device and the Gemini corer. An earlier version of this manuscript benefited greatly from three anonymous reviewers. This work is part of T.C. van 
Son's $\mathrm{PhD}$ work and is financed by the Norwegian Ministry of Education and Research.

\section{REFERENCES}

[1] Thrush SF. Spatial Patterns in soft-bottom communities. Trends Ecol Evol 1991; 6: 75-9.

[2] Kraufvelin P, Perus J, Bonsdorff E. Scale-dependent distribution of soft-bottom infauna and possible structuring forces in low diversity systems. Mar Ecol Prog Ser 2011; 426: 13-28.

[3] Buhl-Mortensen L, Buhl-Mortensen P, Dolan MFJ, Dannheim J, Bellec V, Holte B. Habitat complexity and bottom fauna composition at different scales on the continental shelf and slope of northern Norway. Hydrobiologia 2012; 685: 191-219.

[4] Pearson TH, Rosenberg R. Macrobenthic succession in relation to organic enrichment and pollution of the marine environment. Ocean Mar Biol Annu Rev 1978; 16: 229-311.

[5] Gray JS. The ecology of marine sediments: an introduction to the structure and function of benthic communities. Cambridge: Cambridge University Press 1981; pp. 1-185.

[6] Olsgard F. Do toxic algal blooms affect subtidal soft-bottom communities? Mar Ecol Prog Ser 1993; 102: 269-86.

[7] Hyland J, Balthis L, Karakassis I, et al. Organic carbon content of sediments as an indicator of stress in the marine benthos. Mar Ecol Prog Ser 2005; 295: 91-103.

[8] Veríssimo H, Lane M, Patrício J, Gamito S, Marques JC. Trends in water quality and subtidal benthic communities in a temperate estuary: Is the response to restoration efforts hidden by climate variability and the Estuarine Quality Paradox? Ecol Ind 2013; 24: 56-67.

[9] Whittaker RH. Gradient analysis of vegetation. Biol Rev 1967; 42: 207-64.

[10] Halvorsen, R. A gradient analytic perspective on distribution modelling. Sommerfeltia 2012; 35: 1-165.

[11] Shmida A, Wilson MV. Biological Determinants of Species Diversity. J Biogeogr 1985; 12: 1-20.

[12] Southwood TRE. Habitat, the Templet for Ecological Strategies? J Anim Ecol 1977; 46: 337-65.

[13] Southwood TRE. Tactics, Strategies and Templets. Oikos 1988; 52: $3-18$.

[14] Townsend CR, Hildrew AG. Species traits in relation to a habitat templet for river systems. Freshw Biol 1994; 31: 265-75.

[15] Bremner J, Rogers SI, Frid CLJ. Assessing functional diversity in marine benthic ecosystems: a comparison of approaches. Mar EcolProg Ser 2003; 254: 11-25.

[16] Hewitt JE, Thrush SF, Dayton PD. Habitat variation, species diversity and ecological functioning in a marine system. J Exp Mar Biol Ecol 2008; 366: 116-22.

[17] Cochrane SKJ, Pearson TH, Greenacre M, et al. Benthic fauna and functional traits along a Polar Front transect in the Barents Sea Advancing tools for ecosystem-scale assessments. J Mar Syst 2012; 94: 204-17.

[18] Pacheco A, González M, Bremner J, et al. Functional diversity of marine macrobenthic communities from sublittoral soft-sediment habitats off northern Chile. Helgol Mar Res 2011; 65: 413-24.

[19] Oug E, Fleddum A, Rygg B, Olsgard F. Biological traits analyses in the study of pollution gradients and ecological functioning of marine soft bottom species assemblages in a fjord ecosystem. J Exp Mar Biol Ecol 2012; 432-433: 94-105.

[20] Aarnio K, Mattila J, Törnroos A, Bonsdorff E. Zoobenthos as an environmental quality element: the ecological significance of sampling design and functional traits. Mar Ecol 2011; 32: 58-71.

[21] Gray JS. Animal-sediment relationships. Ocean Mar Biol Annu Rev 1974; 12: 223-61.

[22] Michaud E, Desrosiers G, Mermillod-Blondin F, Sundby B, Stora G. The functional group approach to bioturbation: The effects of biodiffusers and gallery-diffusers of the Macoma balthica community on sediment oxygen uptake. J Exp Mar Biol Ecol 2005; 326: 77-88.

[23] Norling K, Rosenberg R, Hulth S, Gremare A, Bonsdorff E. Importance of functional biodiversity and species-specific traits of benthic fauna for ecosystem functions in marine sediment. Mar Ecol Prog Ser 2007; 332: 11-23.

[24] Törnroos AM, Bonsdorff E. Developing the multitrait concept for functional diversity: Lessons from a system rich in functions but poor in species. Ecol Appl 2012; 22: 2221-36.
[25] van Son TC, Halvorsen R. Multiple parallel ordinations: the importance of choice of ordination method and weighting of species abundance data. Sommerfeltia [in press].

[26] Lundblad ER, Wright DJ, Miller J, et al. A Benthic Terrain Classification Scheme for American Samoa. Mar Geod 2006; 29: 89-111.

[27] Chevenet F, Doléadec S, Chessel D. A fuzzy coding approach for the analysis of long-term ecological data. Freshw Biol 1994; 31: 295-309.

[28] Økland R. Rescaling of ecological gradients. I. Calculation of ecological distance between vegetation stands by means of their floristic composition. Nord J Bot 1986; 6: 651-60.

[29] Van der Maarel E. Transformation of cover-abundance values in phytosociology and its effects on community similarity. Vegetatio 1979; 39: 97-114.

[30] R Development Core Team. R: A Language and Environment for Statistical Computing. Vienna, Austria: R Foundation for Statistical Computing; 2012.

[31] Oksanen J, Blanchet FG, Kindt R, et al. Community ecology package, "vegan" version 2.0-4. 2012.

[32] Pearson K. On lines and planes of closest fit to systems of points in space. Philos Mag 1901; 2: 559-72.

[33] Ter Braak CJF, Prentice IC. A Theory of Gradient Analysis. Adv Ecol Res 1988; 18: 271-317.

[34] Minchin PR. An evaluation of the relative robustness of techniques for ecological ordination. Vegetatio 1987; 69: 89-107.

[35] Hill MO. DECORANA - A FORTRAN program for detrended correspondence analysis and reciprocal averaging. USA: Cornell University 1979.

[36] Hill MO, Gauch HG Jr. Detrended correspondence analysis: an improved ordination technique. Vegetatio 1980; 42: 47-58.

[37] Schönemann PH, Carroll RM. Fitting one matrix to another under choice of a central dilation and a rigid motion. Psychometrika 1970; 35: 245-55.

[38] Økland R, Økland T, Rydgren K. Vegetation-environment relationships of boreal spruce swamp forests in Østmarka Nature Reserve, SE Norway. Sommerfeltia 2001; 29: 1-190.

[39] Olsgard F. Overvåkning av forurensningssituasjonen i Indre Oslofjord. Undersøkelser av bløtbunnsfauna 1993. Oslo: Biologisk institutt, Universitetet i Oslo 1995.

[40] Probert PK. Disturbance, sediment stability, and trophic structure of soft-bottom communities. J Mar Res 1984; 42: 893-921.

[41] Reise K. Sediment mediated species interactions in coastal waters. J Sea Res 2002; 48: 127-41.

[42] Graf G, Rosenberg R. Bioresuspension and biodeposition: a review. J Mar Syst 1997; 11: 269-78.

[43] Montserrat F, Colen CV, Degraer S, Ysebaert T, Herman PMJ. Benthic community-mediated sediment dynamics. Mar Ecol Prog Ser 2008; 372: 43-59.

[44] Grabowski RC, Droppo IG, Wharton G. Erodibility of cohesive sediment: The importance of sediment properties. Earth-Sci Rev 2011; 105:101-20.

[45] Rosenberg R. Benthic marine fauna structured by hydrodynamic processes and food availability. J Sea Res 1995; 34: 303-17.

[46] Murray JM., Meadows A, Meadows PS. Biogeomorphological implications of microscale interactions between sediment geotechnics and marine benthos: a review. Geomorphology 2002; 47: 15-30.

[47] Grémare A. Feeding, tube-building and particle-size selection in the terebellid polychaete Eupolymnia nebulosa. Mar Biol 1988; 97 : 243-52.

[48] Mirza FB, Gray JS. The fauna of benthic sediments from the organically enriched Oslofjord, Norway. J Exp Mar Biol Ecol 1981; 54:1 81-207.

[49] Bagøien E, Kaartvedt S, Øverås S. Seasonal vertical migrations of Calanus spp. in Oslofjorden. Sarsia 2000; 85: 299-311.

[50] Berge JA, Andersen T, Amundsen R, et al. Overvåkning av forurensningssituasjonen $\mathrm{i}$ indre Oslofjord 2008. Oslo: Norsk Insititutt for Vannforskning (NIVA); 2009.

[51] Berge JA, Amundsen R, Bergland K, et al. Overvåkning av Indre Oslofjord i 2011 - Vedleggsrapport. Oslo: Norsk Insititutt for Vannforskning (NIVA); 2012.

[52] Hall SJ. Physical disturbance and marine benthic communities: life in unconsolidated sediments. Ocean Mar Biol Annu Rev 1994; 32: 179-239. 
[53] Post AL, Wassenberg TJ, Passlow V. Physical surrogates for macrofaunal distributions and abundance in a tropical gulf. Mar Freshw Res 2006; 57: 469-83.

[54] Rhoads DC, Boyer LF. The effects of marine benthos on physical properties of sediments: a successional perspective. In: McCall PL,
Tevesz M, Eds. Animal-Sediment Relations. New York: Plenum 1982; pp. 3-52.

[55] Gallagher ED, Jumars PA, Trueblood DD. Facilitation of softbottom benthic succession by tube builders. Ecology 1983; 64: 1200-16

Received: June 11, 2013

(C) Son et al.; Licensee Bentham Open.

This is an open access article licensed under the terms of the Creative Commons Attribution Non-Commercial License (http://creativecommons.org/licenses/by$\mathrm{nc} / 3.0 /$ ), which permits unrestricted, non-commercial use, distribution and reproduction in any medium, provided the work is properly cited. 